East African Medical Journal Vol. 79 No. 2 February 2002

ALCOHOLISM AND DIABETES MELLITUS: CASE REPORT

C.F. Otieno, MBChB, M.Med, Int.med (UoN), Specialist Physician/Lecturer; Department of Medicine, College of Health Sciences, University of Nairobi, P.O. Box 19676, Nairobi, M. M. O. Okonji, MBChB, DPM, MRCPsych.(UK) Consultant Psychiatrist in Private Practice/Formerly Deputy Director of Medical Services, Ministry of Health, Kenya P. O. Box 50458, Nairobi and I. S. O. Odongo, MBChB, MMed Int. Med (Nbi), Specialist Physician, Mbagathi District Hospital, Ministry of Health, Nairobi, Kenya.

Request for reprints to: Dr.C.F. Otieno, Department of Medicine, College of Health Sciences, University of Nairobi, P.O. Box 19676, Nairobi.

\title{
ALCOHOLISM AND DIABETES MELLITUS: CASE REPORT
}

\section{F. OTIENO, M. M. O. OKONJI and I. S. O. ODONGO}

\begin{abstract}
SUMMARY
Two male patients with diabetes mellitus and alcohol dependence syndrome are presented. Both were married and in middle age. MI stayed alone in the city while his spouse and two children lived in the rural home. He showed no obvious underlying psychiatric morbidity. FWK was living with his family in the city. He was an alcoholic receiving psychiatric care for alcoholism. They both presented separately at different hospitals with decompensated diabetes following heavy alcohol consumption. The history and clinico-laboratory picture of both patients are presented and brief management programme and outcome are also given. Review of literature on alcoholism and its potential impact on the course and management of diabetes is presented.
\end{abstract}

\section{INTRODUCTION}

Historically, alcohol use by diabetic patients has been controversial. As long ago as the 17 th century, alcohol has been thought to be a cause of diabetes mellitus. However, alcohol was even used in the preinsulin era to reduce ketones in type I diabetic patients(1). Joslin urged caution in the use of alcohol by his diabetic patients(2).

Acute heavy alcohol intake causes intoxication characterised by abnormal behaviour and impaired judgement and nerve function and may even cause coma. Chronic heavy alcohol intake causes both physical and psychological dependence, with adverse effects on the liver, the heart, the nervous system and perceptual functions. Alcohol withdrawal symptoms include tremors, fits, and/ or hallucinosis(3). If these symptoms occur with diabetes mellitus following alcohol intake there may be such overlaps that can complicate proper recognition of symptoms due to acute diabetic urgencies/emergencies by the first line of help, that is, the patient's family or close associates with disastrous consequences.

Two cases of diabetic patients who were alcoholdependent are presented and their social and clinical aspects discussed in the light of the available evidence.

\section{CASE REPORT}

Case 1: M1 was a 31 year old male clerk in a government corporation who had been a diabetic for two years. He was admitted to a private hospital (NWH) within Nairobi in a very ill state. He admitted to alcohol abuse and erratic insulin intake over the past two years. It was not corroborated how much and for how long he had been abusing alcohol. He had (one year earlier) previously been admitted to the hospital in severe hyperglycaemia after he had skipped insulin injection for an unspecified number of times. He had been unavailable for follow up of his diabetes.

He was staying alone in the city while his wife and two children lived in their rural home. In each of the two occasions of hospitalisation, he was brought in by work-mate friends who found him ill by chance.

This hospitalisation came with complaints of periumbilical abdominal pain, vomiting and reluctantly agreed that he had been drinking a lot of alcohol prior to onset of the pain which had been of a rapid onset and progression without any obvious source of relief. This is what actually prompted the need for urgent medical attention. No haematemesis was reported. He had not used any non-steroidal nor steroidal anti-inflammatory drugs.

On arrival at the out-patient department, he was definitely intoxicated with obvious smell of alcohol in his breath. He was conscious but confused, he had a slurred speech of alcohol intoxication. He was quite restless from the abdominal pain. Pupils were normal and ocular fundi showed no papilloedema. There was no paresis. He was neither pale nor jaundiced. The temperature was $37.5^{\circ} \mathrm{C}, \mathrm{B}, \mathrm{P} .70 / 40 \mathrm{mmHg}$ supine, pulse rapid at $112 \mathrm{bpm}$, regular, respiration was Kussmaul type at $30 / \mathrm{min}$. A fast glycaemic assay was $24.7 \mathrm{mmol} / 1$, a dipstick urine examination showed ketonuria $(++++)$. He had both epigastric and supraumbilical tenderness with guarding but not re-bounding. There was mild ascites. Clinical impression was made of diabetic ketoacidosis, alcoholic gastritis, alcohol intoxication with possibility of acute alcoholic pancreatitis. The management programme instituted included intravenous fluids - normal saline and Hartmann's solution, and insulin therapy, analgesics including intravenous tramadone (a non-narcotic analgesic) and ranitidine for gastric acid suppression. He responded well; within the first 24 hours of treatment the blood pressure picked up to normal, hyperglycaemia decreased and ketonuria turned negative and he also had a successful pain control. He remained confused to the third day but by fourth to fifth days he was lucid enough and he re-established oral intake and became self-ambulant. He was allowed home on insulin with more reinforced diabetic education.

Case 2: FWK was a 53 year old businessman, known diabetic for five years admitted to a private hospital with clinical diagnosis of alcohol dependence, diabetes mellitus in ketosis, chest infection and confusion. Prior to this last admission, he had been hospitalised in a psychiatric hospital for six weeks where he was managed on psychotropics and insulin therapy. He did well, 
consequently he was discharged on treatment. He stayed home for about one week after which he resumed heavy alcohol intake and missed diabetic treatment for this one week. At this last admission he was found to be ill, conscious but confused, dehydrated, acidotic, tinge of jaundice and anaemic. Blood pressure was $130 / 80 \mathrm{mmHg}$, tachycardia of $140 \mathrm{bpm}$. There were no meningeal signs but had bilateral basal chest consolidation. Liver span was reduced to approximately $6 \mathrm{~cm}$, had mild ascites but no splenomegaly. A rapid urinalysis showed ketonuria (+++). Blood $\mathrm{pH}$ was done.

Laboratory reports are summarised below; He was managed on insulin, psychotropics, antibiotics and intravenous fluids. The rapid fall in haemoglobin was not due to any bleeding. His clinical state stabilised initially but on the 6th day he went into a sudden asystole, resuscitation efforts failed and he was certified dead.

Summary of laboratory finding

\begin{tabular}{|c|c|c|c|c|c|c|c|c|}
\hline \multirow[b]{2}{*}{ Parameter (Ref. Range) } & \multicolumn{2}{|c|}{ Day 1} & \multicolumn{2}{|c|}{ Day 3} & \multicolumn{4}{|c|}{ Day 5 Day 6} \\
\hline & MI & FWK & MI & FWK & & FWK & $\mathrm{KFW}$ & \\
\hline \multicolumn{9}{|l|}{ Random blood sugar } \\
\hline$(3.90-5.80 \mathrm{mmol} / \mathrm{l})$ & 24.7 & 20.0 & 13.0 & 19.4 & 10.2 & 7.1 & & D \\
\hline $\mathrm{Na}+(136-148 \mathrm{mmol} / \mathrm{l})$ & 138 & 137 & - & - & $\mathrm{D}$ & & & I \\
\hline $\mathrm{K}+(3.50-5 \mathrm{mmol} / \mathrm{l})$ & 4.3 & 4.80 & - & - & i & & & $\mathrm{e}$ \\
\hline BUN $(0.8-4.0 \mathrm{mmol} / 1)$ & 3.7 & 2.2 & - & - & $s$ & & & $\mathrm{~d}$ \\
\hline \multicolumn{9}{|l|}{ Creatinine } \\
\hline$(35-123 \mathrm{umol} / \mathrm{l})$ & 96 & 95 & - & - & $\mathrm{c}$ & & & \\
\hline $\mathrm{Ca} 2+(2.10-2.60 \mathrm{mmol} / \mathrm{l})$ & 2.20 & 2.0 & - & - & & & & \\
\hline Phosphate (mmol/l) & 0.78 & - & - & & $\mathbf{h}$ & & & \\
\hline Bilirubin - Total: (mg/dl) & 54.4 & 32.3 & - & - & a & & & \\
\hline Direct $(\mathrm{mg} / \mathrm{dl})$ & 15.5 & 23.1 & - & - & $r$ & & & \\
\hline Albumin $(\mathrm{g} / \mathrm{dl})$ & 36.2 & 38 & - & - & $\mathrm{g}$ & & & \\
\hline Gamma-GT (9-54 iu/l) & 203 & 93 & - & - & $\mathrm{e}$ & & & \\
\hline SGPT $(0-40)$ & 27 & 8 & - & - & d & & & \\
\hline SGOT $(15-50)$ & 4 & 26 & - & - & & & & \\
\hline CXR-PA - & \multicolumn{3}{|c|}{ N Pneumonia- } & - & & & & \\
\hline Plain Abdominal Xray & $\mathrm{N}$ & $\mathrm{N}$ & $\cdot-$ & - & - & & & \\
\hline Lipids:- TGs (mmol/1) & 1.70 & 0.74 & -- & - & - & & & \\
\hline$-\mathrm{T} \mathrm{Chol} \mathrm{(TC)} \mathrm{(mmol/l)}$ & 2.00 & 1.50 & - & - & & & & \\
\hline - LDL (mmol/l) & 1.5 & 0.80 & - & - & - & & & \\
\hline - HDL (mmol/l) & 1.10 & 0.70 & - & - & - & & & \\
\hline Serum Amylase (iu/l) & 1647 & 952 & - & - & 128 & - & - & \\
\hline \multicolumn{9}{|l|}{ Blood count: } \\
\hline$-\mathrm{WBC}\left(\times 10^{9} / 1\right)$ & 15.1 & 11.8 & 22.1 & & & 11.2 & & \\
\hline$-\mathrm{Hb}(\mathrm{g} / \mathrm{dl})$ & 13.4 & 16.4 & 12.4 & & & 10.4 & & \\
\hline HbAlc (\%) & $12 \%$ & $6.74 \%$ & - & & - & - & - & \\
\hline $\mathrm{ECG}$ & $\mathrm{N}$ & $\mathrm{N}$ & - & & - & - & - & \\
\hline Urinary ketones & ++++ & ++++ & ++ & ++ & Nil & $\mathrm{Nil}$ & & \\
\hline
\end{tabular}

Abbreviations: $\mathrm{N}=$ Normal; $\mathrm{CXR}$ - Chest $\mathrm{X}$-ray - posteroanterior; $\mathrm{WBC}=$ white blood cells; $\mathrm{BUN}=$ blood urine nitrogen; $\mathrm{TC}=$ total cholesterol; $\mathrm{TGs}=$ Triglycerides; $\mathrm{HDL}=$ high density lipoproteins; $\mathrm{LDL}=$ low density lipoproteins; $\mathrm{Hb}=$ haemoglobin; $\mathrm{GGT}=$ Gamma Glutamyltranspeptidase

\section{DISCUSSION}

These two patients demonstrated a lifestyle of alcohol dependence, lacking in treatment compliance that was not compatible with good health in diabetes. MI was an alcoholic who lived alone. FWK was simply an alcoholic for many years and lived with his family. Good patient compliance or adherence to treatment is paramount in management of diabetes mellitus(4), this was evidently lacking in both patients. A good family and social support is equally important in achieving good control in insulinrequiring diabetes, which has been shown that within the family, higher level of social support to insulin-dependent children is associated with better control $(5,6)$, an observation which has also been shown to apply in adults $(7,8)$. MI stayed alone but survived on the benevolence of friends, who were not staying with him. FWK was often brought by his brother or son for hospitalisation. A stable social support system seems to have been inadequate for both patients in their respective lives.

At glyco-haemoglobin (HbAlc) of 12\%, MI's diabetic control was certainly far from acceptable range. FWK was hospitalised too often where his diabetic treatment was closely supervised, that explains a very good level of glyco-haemoglobin of $6.74 \%$. Erratic insulin injections and the foregoing social environment for MI may explain his poor glycaemic control.

They both developed clinical problems of ketoacidosis, acute pancreatitis and gastritis possibly attributable to excessive alcohol ingestion prior to hospitalisation. Heavy alcohol intake is a known cause of ketoacidosis $(9,10)$ and acute pancreatitis(11). Heavy alcohol intake also elevates triglycerides by inhibiting fatty acid synthesis in the liver. In diabetes mellitus, free fatty acids are reversibly increased during poor control and ketoacidosis. However, with the likelihood of familial dyslipidaemia which usually occur with insulin resistance, also a frequent feature of diabetes mellitus, the rise in triglycerides may be critically high, enough to cause pancreatitis(1). The triglycerides were however, not elevated in these patients. Cognisance is taken of the fact that pancreatitis is not always the cause of hyperamylasaemia in diabetic ketoacidosis, where the isoenzymes of salivary amylase, have been shown, may predominate(12).

Erratic or skipping insulin injections like these patients had, is also known to be a major cause of diabetic ketoacidosis(12) and generally, poor diabetic control(4). Diabetic ketoacidosis still carries high mortality in developing countries(7), FWK did not survive while MI survived this episode, but at a significant cost of hospitalisation which was at best preventable.

Effects of alcohol have been studied in other acute situations in diabetes, like its hypoglycaemic potential(13) and chronically, observed to worsen neuropathic symptoms (14). Heavy alcohol ingestion acutely suppresses gluconeogenesis even in normal individuals. A normal but malnourished person with depleted hepatic glycogen stores would experience hypoglycaemia after heavy alcohol ingestion, which may be enhanced by disordered pituitaryadrenal axis and sympathetic nervous system that exist in chronically malnourished patients(15). These two patients came in hyperglycaemic state therefore the hypoglycaemic risk was not imminent unless treatment-related. However hypoglycaemia is just as serious a complication of alcohol. especially when alcohol abuse has been shown also to enhance hypoglycaemia unawareness in diabetics $(16)$, which is a rather dangerous condition to occur with acute alcohol 
intoxication. The latter may mask the potentially fatal but very treatable condition of hypoglycaemia. Even at relatively low doses, alcohol may induce hypoglycaemia despite low serum insulin levels and high serum glucagon levels(1). This observation implies that it is difficult to determine a threshold of alcohol intake that would either be "safe" or potentially toxic to an individual patient with diabetes mellitus. The fact that different brands of alcoholic drinks contain varying concentrations of alcohol serve to complicate the picture further on how much and what alcoholic drink should be allowed to a patient with diabetes mellitus.

\section{CONCLUSION}

MI survived a potentially avoidable hospitalisation. FWK succumbed to multiple complications of alcoholism with diabetes at the prime of his life. It has been reported in several reviews and a prospective cohort, population studies that modest alcohol intake has mitigating effects on coronary heart disease in diabetes. Modest alcohol intake is thought to mitigate cardiovascular mortality though increase in HDL-cholesterol, increased fibrinolysis, reduced platelet aggregation and reducing insulin resistance(17). These effects of modest alcohol intake would be relatively more pronounced in a diabetic who has increased risk of cardiovascular mortality. However, alcohol abuse or alcoholism seems to constitute quite a different combination with diabetes mellitus which can be fatal(18). Heavy alcohol intake acutely causes complications that warrant costly hospitalisation while chronically may abet long-standing poor glycaemic control through poor treatment compliance and tearing apart the social fabric of the family that should provide a basic and useful psychological support.

Management of the acute diabetic complications with alcoholic effects also involved is generally not different from those without alcohol ingestion. The challenge lies in the treatment of alcoholism and the subsequent rehabilitation of such patients, and creating good diabetic self-care in them, if one ever survives an episode of acute alcohol intoxication and decompensated diabetes. Certainly, a minimum of diabetes physician and a psychiatrist is required, and TIME. The costs involved are high and potentially not sustainable in a life-long disease like diabetes, worse for patients who live in environments that are perennially resource poor.

"A diabetic who knows most about his illness lives longest", said Joslin(2). Patient empowerment through diabetic education is still key to good glycaemic control(19). Alcoholism may not allow a diabetic patient either to regularly attend follow up clinics or to inculcate the tenets of diabetic education and convert them to practical beneficial self-management. Once again, the recommendation regarding alcohol intake falls on the shoulders of the treating physicians who, for various reasons, may not have adequate time to discuss lifestyle issues with their patients(20). About 50\% of alcohol drinkers will experience some alcohol-related problems in their lifetime(3). Alcohol recommendation, therefore, should be judicious and individualized, especially taking into consideration the family, associates and other relevant people in one diabetic patient's life and the relationships thereof. The challenge to the health care provider is major as the options are scarce. This is because there are pieces of evidence for both (danger and) benefits of alcohol(ab)use in diabetes while the dividing line is particularly thin and difficult to discern.

\section{ACKNOWLEDGMENTS}

We are grateful to the medical advisory councils of the two private hospitals for allowing use of the records of their respective patients that formed the basis of this publication. We are most grateful to Rachel Muugi for secretarial services.

\section{REFERENCES}

1. Bell D. Alcohol and the NIDDM patient. Diabetes Care. 1996; 19:509-513.

2. Sharad P. Alcohol and diabetes. In practical management of diabetes, Sharad Pendsey. Jaypee Brothers Medical Publishers, New Delhi (1997) pp 41 .

3. Shuckit M.A. Alcohol and alcoholism. In Braunwald E., Isselbacher K.J., Petersdorf R. E., Wilson J. D., Martin J. B., Fauci A. S., eds. Harrison's Principles of internal medicine. New York, NY, McGrawHill Book Co. (1987): pp 2106-2111.

4. Morris A. D. and Boyle D.I.R. et al: Adherence to insulin treatment, glycaemic control and ketoacidosis in insulin dependent diabetes mellitus. Lancet 1997; 350:1501-1510.

5. Hanson C. L., Henggeler S. W. and Burgen G.A. Social competence and parental support as mediators of link between stress and metabolic control in adolescents with insulin dependent diabetes. J. Consult. Clin. Psychol. 1987; 55:529-533.

6. Schlenk E. A. and Hart L. K. Relationship between health locus of control, health value and social support and compliance of persons with diabetes mellitus. Diabetes care. 1984; 7:566-574

7. Edelstein J. and Linn M. W. The influence of family on control of diabetes. Soc. Science Med 1985; 21:541-544.

8. Schafer L. C., McCaul K. D. and Glasgow R. E. Supportive and nonsupportive family behaviour: relationships to adherence and metabolic control in patients with type l diabetes. Diabetes Care 1986;9:179-185.

9. Lu W.T., Chen K. W., Lin J. D., Huang H. S., Lee C. R. and Huang R. S. Ketoacidosis with hyperglycaemia in heavy drinkers: A report of 12 cases. Chang-Keng: Htsuen lsa Chih. 1997; 20:34-38.

10. Thompson C. J., Johnson D. G., Baylis P. H. and Anderson J Alcoholic ketoacidosis: An underdiagnosed condition? Brit. Med.J. 1986; 292:463-465.

11. Steinberg W. and Tenner S. Acute Pancreatitis. N. Engl. J. Med. 1994; 330: $1198-1210$.

12. Warsaw A. L., Feller E. R. and Lee K. H. On the cause of raised serum amylase in diabetic ketoacidosis. Lancet. 1997; i:929-931.

13. Wash C. H. and Sullivan D. J. Effects of moderate alcohol intake on control of diabetes. Diabetes $1974 ; 23: 440-442$.

14. McCulloch D. K., Campbell I. W., Prescott R. J. and Clarke B. F. Effect of alcohol intake on symptomatic peripheral neuropathy in diabetic men. Diabetes Care. 1980; 3:245-247.

15. Lebowitz H. E. Diabetes ketocidosis. Lancet 1995; 345:767-772.

16. Meeking D. R. and Cavan D. A. Alcohol ingestion and glycaemic control in patients with insulin-dependent diabetes mellitus. Diabet. Med. 1997; 14:279-283.

17. Yki-Jarvienen H., Kovesti V.A., Yli-Kahn R. and Tashkinen M. K. Acute effects of alcohol and acetate on glucose kinetics in normal subjects. Am J Physiol. 1988; 254: E175-E180.

18. Heslop A. J., Davies T. L., Campbell I. W. and Nawroz I. M. Alcohol and diabetes: 'a dangerous cocktail' Pract. Diabet Internat. 1999; 16: $155-156$.

19. Brown F. Patient empowerment through education. Prof-Nurse. 1997; 13 (3suppl):54-56.

20. Criqui M. H. and Golomb B.A. Should patients with diabetes drink to the their health? J. Amer. Med. Assoc. 1999; 282:279-280. 